\title{
Erratum
}

\section{Erratum to "Foraging Habitat Distributions Affect Territory Size and Shape in the Tuamotu Kingfisher"}

\author{
Dylan C. Kesler \\ Department of Fisheries and Wildlife Sciences, University of Missouri, Columbia, MO 65211, USA \\ Correspondence should be addressed to Dylan C. Kesler; keslerd@missouri.edu \\ Received 1 August 2014; Accepted 21 October 2014; Published 29 October 2014 \\ Copyright (c) 2014 Dylan C. Kesler. This is an open access article distributed under the Creative Commons Attribution License, \\ which permits unrestricted use, distribution, and reproduction in any medium, provided the original work is properly cited.
}

This erratum corrects a citation for a related work that used some of the same data. Citation 56 should be included in the References section. After the second sentence of the second paragraph of the Discussion section, a sentence should appear: "Patterns reflect those presented previously $[28,56]$." The third sentence of the third paragraph of the Discussion section should include the citation so that it reads "...or because travel costs associated with food gathering are too great [56]." The fourth sentence of the fifth paragraph of the Discussion section should include the citation so that it reads "... a second population could be established $[28,56]$."

The references were as follows.

[28] G. L. Coulombe, D. C. Kesler, and A. Gouni, "Agricultural coconut forest as habitat for the critically endangered Tuamotu Kingfisher (Todiramphus gambieri gertrudae)," Auk, vol. 128, no. 2, pp. 283-292, 2011.

[56] G. L. Coulombe, Resource selection and space use of the critically endangered Tuamotu Kingfisher, [M.S. thesis], University of Missouri, Columbia, USA, 2010. 

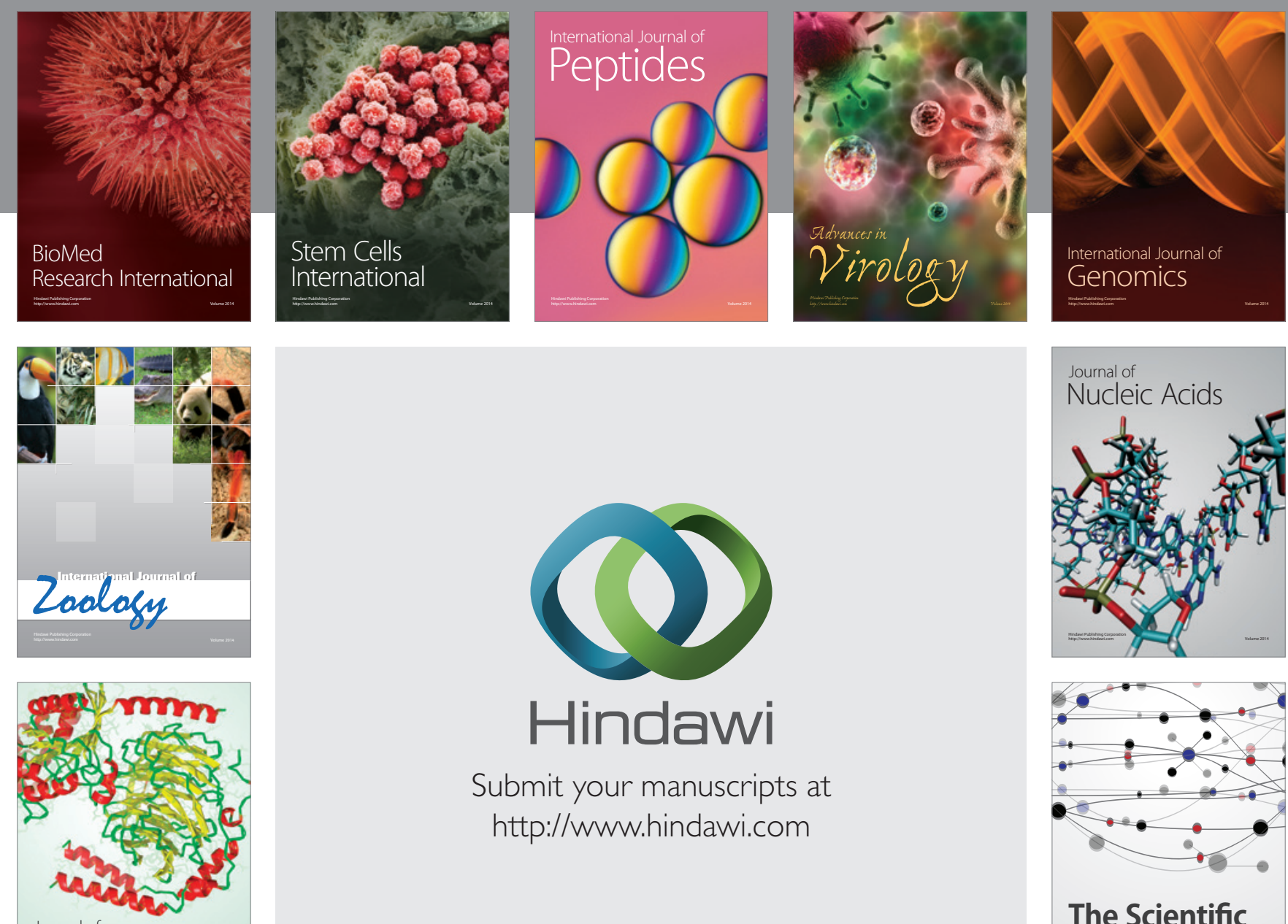

Submit your manuscripts at

http://www.hindawi.com

Journal of
Signal Transduction
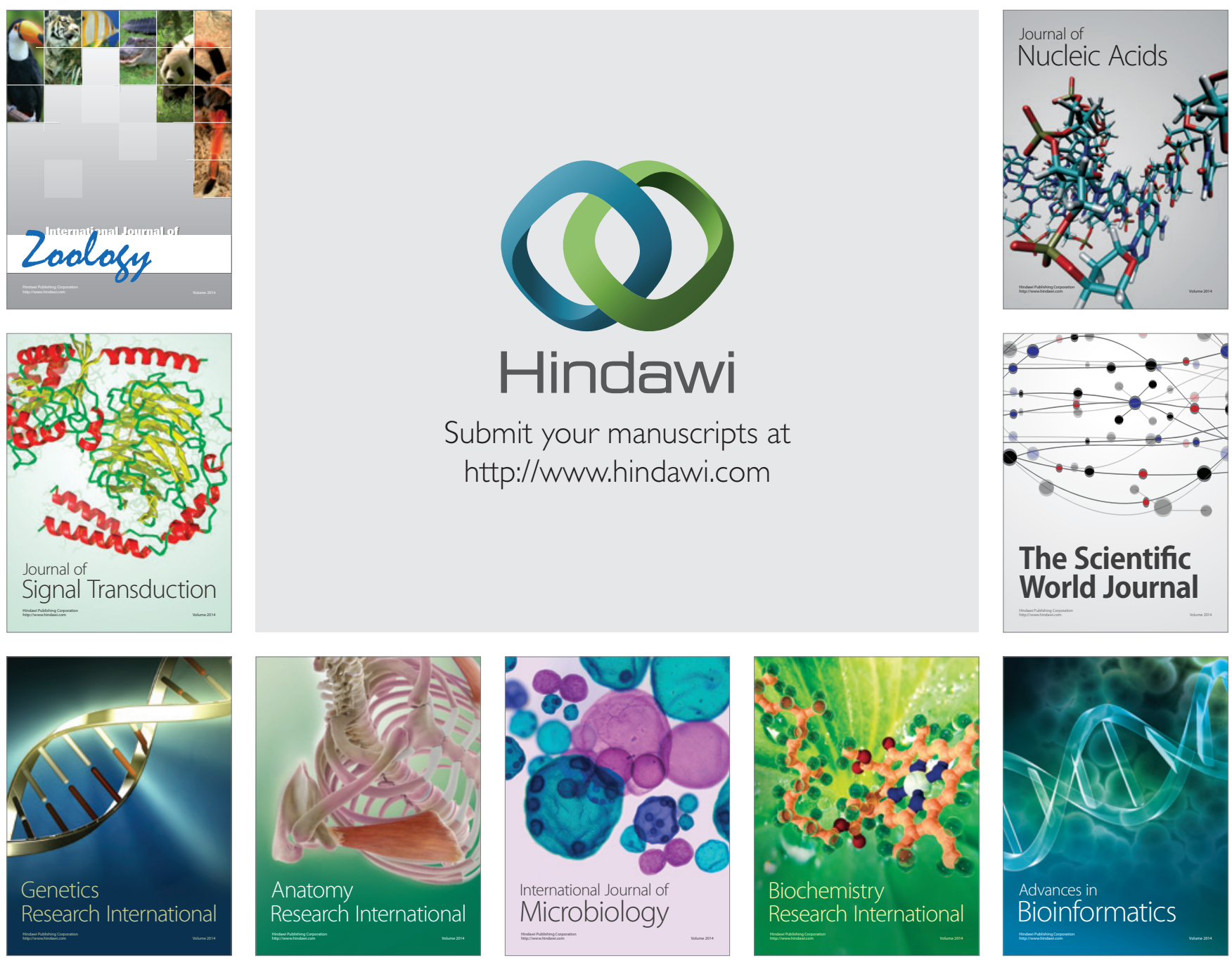

The Scientific World Journal
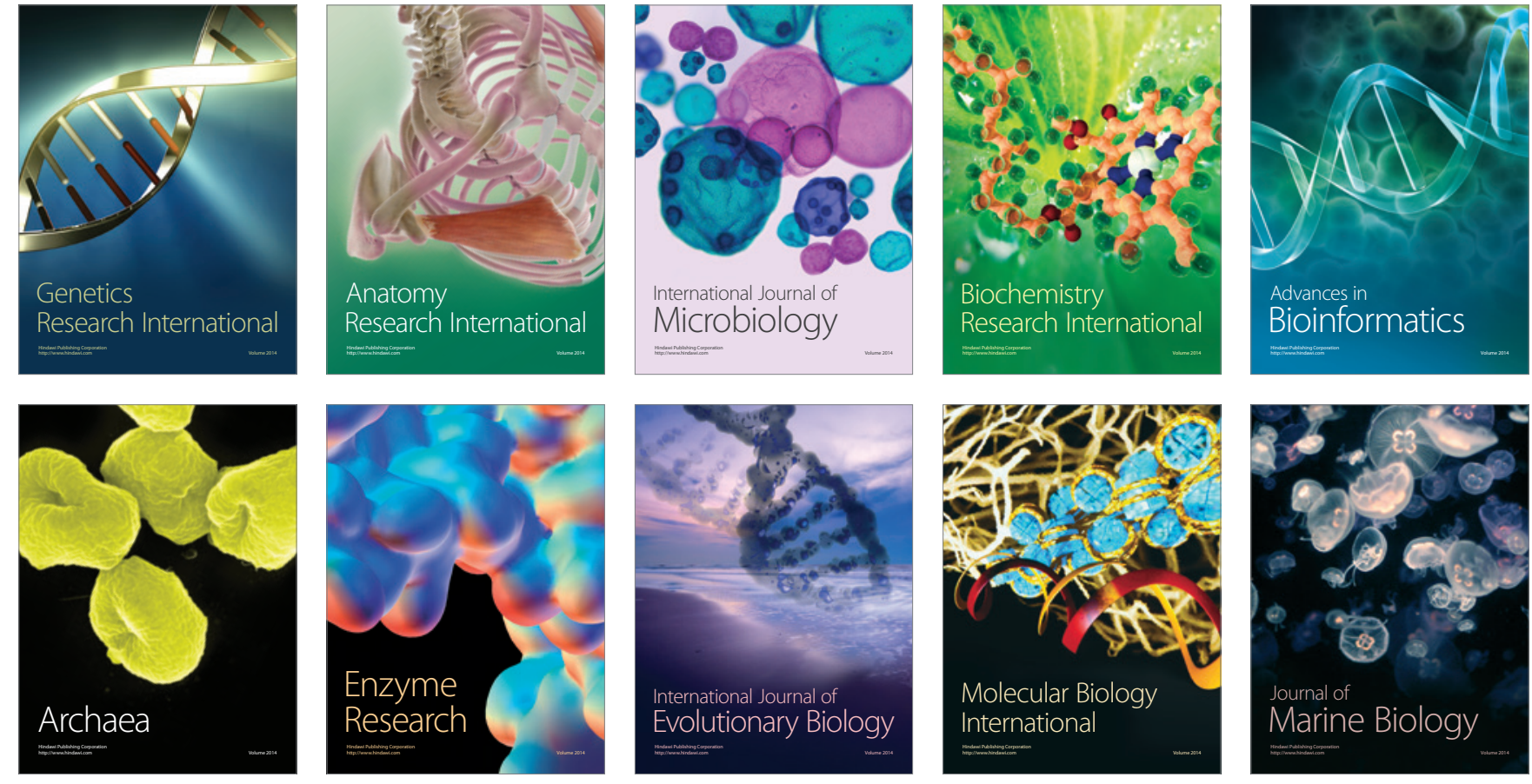